Didáctica. Lengua y literatura

ISSN: 1130-0531

http://dx.doi.org/10.5209/DIDA.61961

\title{
Estrategias para el desarrollo de la expresión escrita a través de los microrrelatos
}

\author{
Ramón Pérez Parejo ${ }^{1}$
}

Recibido: 11 de marzo de 2016 / Aceptado: 29 de septiembre de 2016

Resumen. Los objetivos de este estudio son, de un lado, mostrar los principales debates teóricos en torno al género del microrrelato (breve historia, denominación, distinción con respecto a otros géneros, características esenciales) y, de otro, diseñar un plan de trabajo para llevar a cabo un taller literario de microrrelatos. El microrrelato presenta una cualidad que lo convierte en género idóneo para el taller literario. Nos referimos a su condición de texto breve pero acabado, completo. Por sus características genéricas, la enseñanza de los microrrelatos presenta algunos de los criterios generales de una buena actividad: reto, creatividad, imaginación, carácter lúdico, trabajo en grupo e individual, desarrollo de las cuatro destrezas comunicativas, creación de materiales auténticos, etc. Mostramos finalmente una propuesta de intervención didáctica basada en una metodología constructivista inspirada en el descubrimiento guiado.

Palabras clave: Microrrelato; didáctica; destrezas; práctica pedagógica; escritura.

\section{[en] Learning Strategies for the Development of Writing Skills Using Flash Fiction}

\begin{abstract}
This study intends, on the one hand, to show the main theoretical debates about the genre of flash fiction (history, designation, distinction from other genres, material) and, secondly, design a work plan to carry out a literary workshop on short stories at a secondary school level. These conclusions have let us deduce the highly successful use of flash fiction to develop not only reading comprehension skills but also written expression. Flash fiction have a quality that makes them an ideal genre for a writing workshop: the text provided is brief but it is finished, complete. By its generic characteristics, flash fiction share good teaching features with good activities: challenge, creativity, imagination, playfulness, group work and individual development of the four communicative skills, using of authentic materials, etc. Finally, we show a proposed educational intervention based on a constructivist methodology inspired by guided discovery.
\end{abstract}

Keywords: Flash fiction; didactics; skills; teaching experience; writing.

\section{[fr] Stratégies pour le développement de l'expression écrite par micronouvelles}

Résumé. Les objectifs de cette étude sont, d'une part, présenter les principaux débats théoriques sur le genre de la micronouvelle (le nom, la distinction des autres genres, caractéristiques essentielles) et, d'autre part, la conception d'un plan de travail pour faire un atelier de micronouvelle. La micronouvelle

\footnotetext{
1 Departamento de Didáctica de las Ciencias Sociales, de las Lenguas y de las Literaturas. Universidad de Extremadura (España)

E-mail:rpp@unex.es
} 
a une qualité de texte bref mais fini, complet. Pour leurs caractéristiques génériques, l'enseignement de micronouvelle présente quelques-uns des critères généraux de bonne activité: la créativité, l'imagination, le jeu, le travail de groupe et le développement individuel des quatre compétences linguistiques, en créant des matériaux authentiques, etc. enfin, nous montrons une intervention éducative basée sur une méthodologie constructiviste inspirée par la découverte guidée.

Mots-clés: Micronouvelle ; l'enseignement ; compétences ; pratique pédagogique ; écrit.

Sumario. 1. Introducción. Algunas claves didácticas del microrrelato. 2. Breve historia del subgénero. 3. Hacia la constitución de un género: denominación y autonomía. 4. Características esenciales y características frecuentes. 5. Algunos estudios destacados sobre la didáctica del microrrelato. Hacia un escenario comunicativo. 6. Propuesta didáctica. 7. Resultados. Notas para un taller de microrrelatos. 8. Guía-decálogo para escribir un microrrelato en 10 pasos. 9. Conclusiones. 10. Bibliografía.

Cómo citar: Pérez Parejo, R. (2018) Estrategias para el desarrollo de la expresión escrita a través de los microrrelatos, Didáctica. Lengua y literatura, 30, 169-183.

\section{Introducción. Algunas claves didácticas del microrrelato}

Conviene comenzar con algunas claves didácticas de este género literario cada vez más en boga en la literatura contemporánea occidental, el cual constituye un interesante recurso educativo (Tomassini y Colombo, 1999). El género, sin duda, se adecúa al currículum de Educación Secundaria así como al nivel C1 del Marco Común de Referencia Europeo puesto que desarrolla las macrohabilidades o destrezas lingüísticas tanto en lengua materna como en la enseñanza de la segunda lengua (Fernández-Cuesta, 2012, 37; Lahoz, 2011, 26-35; Bamidele, 2010, 58-64). Son indudables sus bondades para incentivar el gusto por la literatura de ficción a través de pequeñas dosis. En contraste con otros tipos de textos escolares, los microrrelatos no son extractos de obras superiores, sino textos cerrados y autónomos que, además, incorporan la motivación del reto, pues se trata siempre de lecturas exigentes. En efecto, el microrrelato entrena al lector en sus estrategias de lectura; posee, como afirma Larrea, las "condiciones textuales para articular un lector competente" $(2004,179)$.

Por otro lado, el microrrelato se presta a interesantes actividades grupales (Rondón, 2014) y resulta, como indica Bamidele, "muy compatible para los mecanismos de la literatura digital" $(2010,63)$ a través concursos literarios nacionales cada vez más comunes en Internet, en concreto con el uso de redes sociales tipo Twitter.

Seguidamente expondremos la teoría básica acerca del género del microrrelato (historia, debate acerca de su denominación, características, tipología, etc.), tras la que mostraremos una propuesta de intervención didáctica basada en una metodología constructivista inspirada en el descubrimiento guiado. La experiencia se ha llevado a cabo en el I.E.S. "Castillo de Luna" de Alburquerque (Badajoz).

\section{Breve historia del subgénero}

Desde el inicio de la literatura han aparecido textos escritos u orales de corta extensión: fábulas, apólogos, apotegmas, casos, adivinanzas, leyendas, parábolas, refra- 
nes, epitafios, retahílas, sentencias, máximas, aforismos, chistes, anécdotas. Todos ellos conforman, como dice Luis Landero, "el fruto más antiguo del viejo oficio de narrar" $(2007,11)$. No hay tradición cultural que no haya producido alguno de estos tipos de microtextos con distintas intenciones.

A grandes rasgos, los antecedentes literarios del microrrelato se localizan en la Edad Media a través de la narrativa didáctica, los bestiarios y las sentencias contenidas, por ejemplo, en El conde Lucanor. Sin embargo, a lo largo de los siglos posteriores, el microrrelato no logra jamás aislarse por completo del resto de subgéneros narrativos cortos ni se vislumbra su constitución o desarrollo como género autónomo.

Hay que esperar al siglo XX para percibir la constitución del microrrelato como género. A ello ayudaron decisivamente las corrientes literarias más innovadoras desde finales del siglo XIX hasta el primer tercio del XX, concretamente en el eje entre Modernismo y Vanguardias. Suelen citarse, entre otros, autores como Rubén Darío, Ramón Gómez de la Serna, Leopoldo Lugones o Julio Torri. No debe extrañar en esta primera nómina la presencia destacada de autores hispanoamericanos.

El desarrollo y concepción definitiva del microrrelato como género nace ligado a los grandes narradores latinoamericanos en torno al medio siglo y al boom de la literatura hispanomericana y, dentro de ellos, al contexto geográfico del Río de la Plata, donde se dan cita autores pioneros del género como Jorge Luis Borges, Adolfo Bioy Casares, Julio Cortázar, etc. Desde ahí se extendería por toda Latinioamérica primero y por Europa después gracias a la conexión editorial con España.

Conviene mencionar al menos los hitos más importantes de este viaje literario (Navascués, 2004; Fernández, 2010). Como ilustre antecedente, en 1940, Silvina Ocampo, Adolfo Bioy Casares y Jorge Luis Borges publican la Antología de la literatura fantástica que contiene numerosos ejemplos de microrrelatos, además de un personalísimo criterio de selección (Navascués, 2004, 121) que tendría mucho que ver en la futura confección del canon. De 1953 es la ya clásica antología $\mathrm{Na}$ rraciones breves y extraordinarias, esta vez a cargo solo de Bioy Casares y Borges, considerada la primera compilación de minificción contemporánea. Más adelante, en el cambio de decenio, varios escritores dejan su impronta en la constitución del género y su difusión por el resto de Latinoamérica y en Europa: Adolfo Bioy Casares escribe Guirnalda con amores (1959), Jorge Luis Borges publica El hacedor (1960) y Julio Cortázar hace lo propio con Historias de cronopios y de famas (1962). Ya solo faltaba que la teoría literaria acudiera a la cita. Como afirma Clara Obligado $(2001,10)$, Borges editó la primera antología del género y a partir de Monterroso los encontró la crítica.

En cuanto a las razones de su proliferación, especialmente en España (Andrés 2007, 12-13), Latinoamérica y Estados Unidos, algunos investigadores explican la creciente difusión del microrrelato "como consecuencia natural de toda una estética de la brevedad que, en realidad, viene fraguándose desde el Modernismo" (Gómez, $2007,8)$ que tiene en la contemporaneidad diversas manifestaciones en todas las artes (Andrés, 2007, 14; Pérez, 2007, 287-325); otros destacan la heterodoxia de la posmodernidad (Hernández Mirón, 2010; Yepes, 1996, 106) que prima el consumo cultural de productos rápidos (Cumbreño, 2007, 15-16; Ródenas, 2008, 7).

En la actualidad el género del microrrelato goza de una creciente y notable atención crítica, de un gran cultivo en todo el mundo y de una legión de seguidores. El interés por el género se refleja en la celebración de numerosos concursos literarios, 
en publicaciones específicas (en todos los soportes), en números monográficos en revistas especializadas, así como en congresos nacionales e internacionales (Gómez Trueba, 2007, 7), de todo lo cual no podemos dar cuenta en estas páginas (Valls, 2008, 2; Andrés, 2007, 14-15).

\section{Hacia la constitución de un género: denominación y autonomía}

El microrrelato ha recibido diferentes denominaciones: microrrelato, microtexto, relato hiperbreve, microficción, casicuento, microcuento, minicuento, cuento minúsculo, cuentículo, flash fiction, etc., pero parece imponerse la de microrrelato. A nuestro juicio, esta última denominación constituye un acierto porque sirve para distinguir el microrrelato de otros tipos de microtextos, al tiempo que señala sus dos características fundamentales: la brevedad y su carácter narrativo. A ellas solo habría que añadir un tercer factor básico: su carácter ficcional.

Así que conviene establecer cuanto antes una distinción que resultará útil para perfilar el género y distinguirlo de otras producciones: la distinción entre microrrelato y microtexto. El microrrelato es un tipo de microtexto. En la categoría "microtexto" incluimos toda aquella producción con rasgos de literariedad (es decir, voluntad de estilo, permanencia, extrañeza, incluidos los textos publicitarios) cuya característica fundamental en cuanto a su extensión es la brevedad entendida esta como un rasgo estilístico con fines específicos. Como afirma Lagmanovich, "los microrrelatos ocuparán una porción del territorio general de los microtextos” $(2008,4)$, con lo cual se acaba de distinguir en relación a otros productos literarios breves y narrativos no ficcionales tales como los eslóganes, los refranes, las sentencias, los aforismos, los dichos, las greguerías, etc. (López Molina, 2008, 17-18; Rivas, 2008, 19-22).

Sin duda, las tres características señaladas son las que presiden la esencia del género. El incumplimiento de cualquiera de ellas anula su consideración como microrrelato. Sin embargo, pueden señalarse otras, también relevantes, que nos permiten distinguir definitivamente los microrrelatos de otros tipos de microtextos. Lagmanovich $(2007,27-28 ; 56-75)$ señala las siguientes:

- Progresión narrativa y uso de los tiempos verbales de la narración, si bien suele haber un rasgo de intemporalidad.

- Enfoque de un incidente o evento individual, o sea, no es una generalización. Cumple, por tanto, la unidad de acción.

- Es irrelevante su relación con el mundo natural, pero obligatoria su vinculación con la naturaleza humana.

Estas pocas características bastarían para distinguir el microrrelato del corpus de numerosos microtextos de extensión limitada: todos los aforismos (que son por definición generalizadores), la mayor parte de las greguerías (que no suelen tener progreso narrativo), los bestiarios medievales (que no se refieren directamente a personas); la prosa publicitaria (no articulada narrativamente), el haiku (que tiene referencias naturales y presenta un evento en su ocurrencia actual), etc. 


\section{Características esenciales y características frecuentes}

Para acabar de delimitar las características esenciales del género, vamos a asomarnos a dos rigurosos estudios que, haciendo honor a la brevedad del género, describen resumidamente sus características. Me refiero a los artículos de Fernando Valls (2007, 117-124) e Irene Andrés (2007, 11-39).

Fernando Valls sintetiza en un preámbulo, un decálogo y una conclusión tanto la historia como las características del género. Como botón de muestra del grado de concisión transcribimos el artículo quinto, titulado "(y casi una definición)":

El microrrelato es un género narrativo breve que cuenta una historia (principio éste irrenunciable), en la que debe imperar la concisión, la elipsis, el dinamismo y la sugerencia (dado que no puede valerse de la continuidad), así como la extrema precisión del lenguaje, que suele estar al servicio de una trama paradójica y sorprendente. Se presta, a menudo, a la experimentación; se vale con frecuencia de la reescritura o lo intertextual; y no debería faltarle la ambigüedad, el ingenio y el humor. Al aislar y centrarse en una sola acción y en torno a unos pocos personajes, se intensifica su sentido cargándose de densidad [...] Su estrategia compositiva, como si de un relámpago de sentido se tratara, consiste en arrancar de inmediato para acabar al instante [...] parte del tejido narrativo debe permanecer elíptico o sobreentendido. Por tanto, si toda la literatura debe componerse borrando, el microrrelato, como la mejor poesía, se ha escrito siempre desechando sin concesiones (Valls, 2007, 119-120).

Por su parte, Irene Andrés (2007, 22-40) analiza también las características de los microrrelatos, algunas de las cuales ya hemos señalado. Sin embargo, mencionamos su estudio porque la agrupación que realiza nos parece sumamente acertada. Establece varios grupos: rasgos formales, rasgos temáticos y rasgos estructurales. Dentro de los formales menciona la brevedad, la sustancia narrativa, la ausencia de descripciones y/o caracterizaciones, su naturaleza elíptica, la concisión y la particular importancia de la elección del punto de vista del narrador. Dentro de los rasgos temáticos, predominan los relatos intertextuales, metaficcionales, satíricos y humorísticos. En cuanto a los rasgos estructurales, vienen determinados por la extensión.

Después de lo apuntado sobre las características del género, poco queda por señalar. Nuestra aportación, en todo caso, se limita a destacar otros rasgos que, aunque se han señalado lateralmente por parte de la crítica, consideramos particularmente relevantes: por un lado su carácter culto; por otro la cuestión de la recepción y, por último, lo que podemos llamar la tendencia a la inestabilidad. Tras ello mencionaremos un listado de otros elementos, si no necesarios, sí muy frecuentes en este tipo de textos.

Tal como ha llegado el microrrelato a nuestras manos en el siglo XXI, puede afirmarse que otra característica capital es que se trata de un género culto. Las posibles filiaciones o antecedentes orales y populares que señalamos al comienzo de este estudio han desaparecido por completo, primero, gracias al filtro culto de la literatura didáctica medieval y, segundo, por el carácter culto de los escritores que lo pusieron en boga a partir de la segunda mitad del siglo XX, sobre todo en Latinoamérica, unos escritores (desde Lugones a Bioy Casares pasando por Borges y Cortázar) que al conformar los rasgos principales del género lo impregnaron de culturalismo y referencias intertextuales, premisas de la literatura culta. 
Hay características del género, algunas ya mencionadas, que están directamente relacionadas con la recepción. El microrrelato suele retar al lector a una actividad hermenéutica de gran calado. Se trata de la movilización de un "mayor número de estrategias completivas" (Ródenas, 2008, 7), lo cual exige un lector disciplinado, suspicaz y dispuesto a cooperar a fin de minimizar la cantidad de incertidumbre informativa. Ródenas $(2008,6)$ insiste en que la lectura de estos textos se asemeja a la de otros textos de la estética del silencio, donde adquiere relevancia lo no dicho, los espacios de silencio anteriores y posteriores del texto. Al ser un género inacabado, incompleto, indeterminado, fragmentario semánticamente hablando, remite casi siempre a la ambigüedad. Quiebra las expectativas del lector, al que impele a seguir buscando el sentido una vez concluido. Además, como afirma Yepes, "obliga al lector a detenerse, a rumiar su actividad descodificadora e impone una pausa reflexiva y recupera el placer de la contemplación" $(1996,99)$.

Ciertos rasgos de los microrrelatos remiten a la inestabilidad desde diversos planos: temático, intertextual, semántico, hermenéutico $\mathrm{y}$, sobre todo, ficcional, entendido como la relación que establece el texto con la realidad objetiva. Numerosos microrrelatos se dirigen directamente a la inestabilidad de las certezas o de las lógicas causales. Ejemplos de temática o elementos recurrentes inestables son los conflictos de identidad y la presencia del doble (Martín, 2008, 9-12), las sombras, las vidas alternativas, los espejos, los laberintos, los sueños, los delirios, las metamorfosis, las imaginaciones, los fantasmas, los vampiros, los zombis, los mundos y seres invisibles, los espíritus, la dualidad o confusión de planos ficcionales, la intervención constante del azar y un larguísimo etcétera. El lector de microrrelatos identificará rápidamente la anterior lista de elementos como protagonistas habituales en el género. Irene Andrés (2007, 32-34) cita otros componentes que remiten a la inestabilidad: la presencia de mundos paralelos y alternativos al nuestro, la interferencia entre lo real y lo soñado, la disolución de fronteras entre el mundo consciente y el inconsciente, la vigilia y el sueño, la vida y la muerte, la incomunicación, la falta de comprensión de fenómenos cotidianos, los vuelcos súbitos de situaciones, los ángulos de visión diferentes, la vulneración de las coordenadas espacio-temporales, todo ello "metáforas de la identidad escurridiza, escindida y múltiple del hombre moderno" (Andrés, 2007, 32). Esta inestabilidad es a lo que Yepes $(1996,96)$ ha llamado "levedad", señalándola también como rasgo constitutivo del género.

Existen además una serie de características importantes que, si no son imprescindibles, sí resultan muy frecuentes. Vamos a citar algunas de ellas intentando agruparlas para su mejor comprensión en dos apartados: elementos y ausencias.

Hay algunos elementos que suelen estar presentes en buena parte de los microrrelatos. Unos están relacionados con la estructura: la importancia y significación de los títulos (que suelen encerrar claves hermenéuticas del texto), los comienzos in medias res, la sorpresa final o los finales abiertos. Al igual que el título, la selección de la voz narrativa (el plano enunciativo) es importantísima en estos textos tan breves porque determina todo el relato. Es muy frecuente la aparición del humor, el ingenio, los diálogos rápidos y lapidarios, la intertextualidad, la parodia y la presentación natural o espontánea de lo maravilloso como en el realismo mágico. La extensión orienta los demás rasgos de estilo: gran intensidad expresiva, esencia, concisión, condensación y, por tanto, prosa muy cuidada. J. R. Santos lo sintetiza así: "Conviene explotar al mínimo los recursos narrativos: elegir la palabra adecuada, modelar con esmero la 
sintaxis, estudiar minuciosamente la trama, todo para lograr la mayor eficacia posible con la cantidad imprescindible de elementos" $(2007,119)$.

Tan importantes como las presencias son las ausencias, es decir, los elementos que no deben aparecer en un microrrelato, mucho más teniendo en cuenta el carácter breve, elíptico y elusivo del género, que basa su eficacia en la síntesis. Quizá la más importante sea la ausencia de digresiones, explicaciones, caracterizaciones, presentaciones de personajes o descripciones. Si las hay tienen una forma totalmente impresionista, escritas mediante breves y súbitos pero efectivos retazos. Como afirma Irene Andrés, "el escritor no dispone de tiempo ni de espacio para caracterizar a los personajes" $(2007,24)$, a lo que habría que añadir que es el lector quien los caracteriza según las acciones o los discursos que lleven a cabo. La otra gran ausencia imprescindible es la de la moraleja. No hay ética ni enseñanza moral explícita en los microrrelatos. Este rasgo le distingue definitivamente de las fábulas. Además, en la inmensa mayoría de los casos tampoco existe una carga moral implícita o latente.

\section{Algunos estudios destacados sobre la didáctica del microrrelato. Hacia un escenario comunicativo}

Aunque, como hemos dicho, existe ya una notable bibliografía sobre el microrrelato, esta se ocupa sobre todo de analizar la historia, los rasgos constitutivos del género o la obra concreta de algunos autores. Sin embargo, son escasos los estudios monográficos dedicados a profundizar en sus posibilidades didácticas, pese a que la Didáctica de la Literatura como disciplina siempre ha recomendado este tipo de composiciones para formar lectores y desarrollar la destreza escrita (García, 1995, 208-209), especialmente a través de talleres literarios convencionales (Sánchez y Rincón, 1984; Latorre Zacarés y Máñez Aracil, 2004) o bien de talleres de cuentos en clase de español como lengua extranjera (Juárez, 1998; Brasca, 2007), entendidos estos como lugares de educación donde se hacen cosas, es decir, donde se pasa de la lección magistral a la escritura de textos como objetivo didáctico.

Insistimos en que desde la teoría literaria apenas se ha atendido al plano didáctico de los microrrelatos. Llama la atención esta ausencia cuando a nadie se le escapan las posibilidades didácticas en torno a la lectura y composición de toda suerte de microtextos. Con todo, podemos señalar algunas aproximaciones didácticas a los microrrelatos. Es de valorar en este sentido el libro editado por la profesora de la Universidad de Salamanca Francisca Noguerol Jiménez, Escritos disconformes. Nuevos modelos de lectura (Noguerol, 2004), que presenta un capítulo dedicado a la didáctica de los microrrelatos titulado "Enseñar con minificción", el cual contiene tres artículos que enfocan la cuestión desde distintas perspectivas: los ambientes hipermediales (H. González), el español para extranjeros (M. E. Lorenzin) y el taller de escritura creativa (C. Obligado). Los comentamos brevemente:

M. E. Lorenzin (2004, 317-333) analiza las posibilidades didácticas de la composición de microrrelatos en la enseñanza del Español para Extranjeros mediante una serie de actividades de carácter lúdico.

H. González (2004, 301-314) describe diversas experiencias interactivas en la red integradas en el Proyecto Himini. Resulta especialmente interesante la que titula "Minificción interactiva", inspirada en la trama narrativa de Las mil y una noches. 
Por último, C. Obligado (2004, 333-343) propone un proyecto de creación de textos hiperbreves desde un taller de escritura. La investigadora resalta las virtudes educativas de la utilización de microrrelatos en la enseñanza. A la hora de realizar un taller literario centrado en el microrrelato no se trata de elegir, "sino de generar, de motivar a la escritura, de expresar las características del género de forma que sirviesen a la vez como material de análisis y disparadores de la creación" $(2004,338)$.

Hay un aspecto que me gustaría destacar: los tres estudios anteriormente citados exhiben los trabajos de los alumnos, cuestión que me parece fundamental para incentivar la creación, ya que en todas las experiencias didácticas el uso del microrelato funciona como un reclamo para el desarrollo de las destrezas lingüísticas (Arias, Calvo y Hernández, 2009).

\section{Propuesta didáctica}

La filosofía educativa que ampara la siguiente propuesta didáctica es el constructivismo, pues los nuevos aprendizajes se desarrollarán sobre los ya adquiridos, mientras que la metodología principal de las actividades de enseñanza-aprendizaje que proponemos están inspiradas en el descubrimiento guiado, ya que comenzaremos por la lectura de textos representativos, tras los cuales, a través de preguntas guiadas, los alumnos descubrirán las características básicas de los microrrelatos. Estos principios están basados en las investigaciones sobre Psicología Evolutiva (Ausubel, Novak y Hanesian, 1983) y de la Instrucción. Parten del nivel de desarrollo del alumno asegurando la construcción de aprendizajes significativos que se generan en el propio alumno y consiguen modificar sus esquemas de conocimiento a través de las relaciones entre el nuevo conocimiento y los esquemas de conocimiento adquiridos. Los nuevos aprendizajes en la propuesta constructivista surgen primero a escala social y más tarde a escala individual (Vigotsky, 1985, 92-94). Quiere decirse que, aunque el aprendizaje es una actividad solitaria, la interacción entre alumnos favorece el avance de Zonas de Desarrollo Próximo porque establece un clima relacional, efectivo y emocional basado en la confianza, la seguridad y la aceptación mutuas (Coll, 1984, 119-138).

La secuencia general, en ocho fases, sería la siguiente:

1. Lectura en clase (en voz alta) de una selección de microrrelatos de autores consagrados. Destrezas implicadas: comprensión oral y/o comprensión escrita.

2. A partir de las lecturas, los alumnos intentan extraer o deducir las características del género. Destrezas implicadas: expresión oral (modalidades: discusión, debate, puesta en común).

3. El profesor compara las características deducidas por los alumnos con un listado académico de características, destacando las más importantes. El profesor felicita a los alumnos por la reflexión crítica (ya que estos descubren con facilidad las características básicas e intuyen buena parte de las más frecuentes). Destrezas: expresión/comprensión oral.

4. El profesor aprovecha el momento, tras la lectura y el descubrimiento de las características, para exponer algunas cuestiones teóricas acerca del género: Debate sobre su denominación, breve historia (antecedentes lejanos, antece- 
dentes próximos, constitución del género); tres distinciones básicas: microtexto/microrrelato; microrrelato/cuento; microrrelato/greguería.; razones de su auge contemporáneo; información sobre concursos literarios en red. Destreza: comprensión oral.

5. Trabajo en grupo: El profesor proporciona una antología de microrrelatos a los alumnos. Puede hacerlo remitiendo a un enlace de Internet, donde pueden hallarse páginas muy recomendables escritas por algunos de los investigadores más avezados en el género (Lagmanovich, 2006). Asimismo puede remitir a un documento propio tipo Google Site o Dropbox donde ha alojado previamente una adaptación de la antología citada (según el nivel de los destinatarios) o una antología creada ex profeso. Los alumnos, en grupo o individualmente, seleccionan un texto y explican por qué les ha gustado ese texto en concreto. También eligen alguno que no les haya gustado porque no se ajuste a las características del género o porque no les haya interesado. Se trata de expresar el gusto personal y, sobre todo, estético. Destrezas: comprensión escrita/expresión oral.

6. El profesor muestra a los alumnos una selección de los relatos que ganaron el concurso en ediciones anteriores. Este es uno de los momentos claves del proyecto porque los alumnos conocen a los autores y, una vez asimiladas las características del género, aprecian y valoran esas producciones literarias que obtuvieron merecidamente la atención de los miembros del jurado y que con el paso de los años se convierten en "clásicos" dentro del centro, ya que siempre se recitan y comentan. Destrezas: comprensión oral y escrita.

7. Taller de creación (Evaluación). Se pide a los alumnos que escriban un microrrelato. Antes el profesor les proporciona un manual de estilo (recomendaciones generales para escribir un microrrelato. Lo haremos aquí también). Se concede un tiempo prudente, generalmente el fin de semana, a fin de que escriban de forma sosegada. El lunes se leen los textos en cada una de las aulas. Destreza: expresión escrita. Opciones:

7.a. Lectura en voz alta de los microrrelatos.

7.b. Escritura de los microrrelatos en un blog o en una revista.

7.c. Concurso literario.

7.c.a. Concurso literario en clase.

7.c.b. Concurso literario en el aula o el centro.

8. Investigación. Se proporciona a los alumnos una serie de materiales, bibliografía y webgrafía a través de los cuales pueden acceder fácilmente a la investigación sobre el microrrelato. Destrezas: comprensión escrita/expresión escrita.

\section{Resultados. Notas para un taller de mircrorrelatos}

Pero vamos a centrarnos ya en la experiencia que queremos presentar. Desde el curso 2004-2005 el I.E.S. "Castillo de Luna" de Alburquerque (Badajoz) viene organizando un certamen literario llamado "Concurso de relatos hiperbreves Luis Landero", paralelo al ya consolidado "Certamen de Narraciones Cortas Luis Landero", cuya primera edición se remonta al curso 1990-1991, convirtiéndose así en el decano de 
los certámenes nacionales de narraciones cortas de este nivel educativo en España. Los trabajos premiados en ambas categorías se publican en una edición de la Editora Regional de Extremadura. La idea de la creación del "Concurso de relatos hiperbreves" partió del grupo de profesores del Departamento de Lengua castellana y Literatura a fin de que los alumnos del centro participaran activamente en los actos que anualmente se celebran en honor al ilustre escritor extremeño.

La idea surge además de la observación de que existía un "Concurso internacional de relatos hiperbreves" organizado por el Centro cultural Faroni de Madrid, que toma el nombre de un singular personaje de la primera novela de Luis Landero, Juegos de la edad tardía (1989). Se conocía, además, el especial afecto de nuestro novelista por este género.

El objetivo de convocarlo en el ámbito educativo no fue otro que el de fomentar la escritura entre los alumnos del I.E.S. "Castillo de Luna" de Alburquerque. En el "Concurso de relatos hiperbreves" participan todos los alumnos matriculados en el centro, animados con la idea de colaborar activamente, cada uno con su grano de arena (en este caso un breve relato) en la organización del día de la proclamación del fallo y la entrega de premios del ya mencionado certamen de narraciones cortas, donde acude puntualmente el escritor Luis Landero.

Los profesores de Lengua Castellana y Literatura, en sucesivas reuniones, seleccionan los trabajos por niveles educativos. Son premiados los dos mejores ejercicios de cada nivel educativo. Los ganadores obtienen como premio un regalo (que suele consistir en algún libro emblemático: la edición conmemorativa de Don Quijote de la Mancha en Espasa-Calpe o la última edición del Diccionario de la Lengua Española de la Real Academia Española) entregado en mano por Luis Landero y, desde 2005, la publicación en la página del instituto y la posibilidad de ver publicado su trabajo en la Editora Regional de Extremadura, lo cual es un premio que excede ampliamente tanto las expectativas de los alumnos como las de los promotores originales del proyecto.

A pesar de los recelos de los alumnos en la primera edición, constatamos que constituyó un éxito, hasta el punto de que los alumnos demandaron con insistencia la organización de una nueva edición. Los profesores responsables, sorprendidos por la acogida, prepararon la segunda edición. El concurso se convirtió entonces en la excusa perfecta para hablar de literatura y de creación literaria, de tal modo que durante los días previos al concurso las clases se convirtieron en verdaderos talleres literarios de forma espontánea, que es la mejor forma de hacerlo. Cada nuevo año son más los alumnos que solicitan información y piden que se hagan ensayos para engrasar la maquinaria creativa. Desde 2005 hasta hoy se viene realizando este certamen.

He aquí una brevísima antología de los microrrelatos seleccionados en el curso 2005-2006, es decir, en la segunda edición:

\section{Alejandro de Matos Salgado. $1^{\circ}$ ESO. C "Sin título"}

Me arrepiento de no haberme quedado mirando. Nunca me lo perdonaré. Volvíamos a casa mis padres, mi hermano y yo tras pasar el fin de semana con los abuelos en el pueblo. Mi abuelo salió de casa a despedirnos. Mi abuela se quedó recogiendo las tazas de café, el cola-cao y los dulces que habíamos comido todos juntos. Por un instante me quedé mirando a mi abuelo cuando levantó la garrota 
y se dio la vuelta para volver a casa. Mi padre encendió la radio mientras hablaba con mi madre de no sé qué y mi hermano me decía algo pero no le prestaba atención. Yo tuve una corazonada. En ese momento supe que no volvería a ver a mi abuelo nunca más. Pero no volví la mirada para verlo una vez más y de eso me arrepentiré toda la vida.

Fco. Alfonso Cancio. $1^{\circ}$ Bachillerato. CC.NN. "Nunca se sabe"

Entre golpes e insultos, su llanto resonó por todo el vecindario. Sólo le dio tiempo a decir: "Yo no te he...". De pronto abrió los ojos y miró a su izquierda. Su marido dormía plácidamente a su lado.

Juan Luis González Rabazo. $1^{\circ}$ Bachillerato. CC.SS. "Última llamada”

Al rato fui consciente de mi estado. Había tenido un accidente de tráfico. Mi coche se aplastaba a 50 metros de la carretera, tras unos matorrales. No podía moverme, apenas podía respirar. Perdía mucha sangre y no me sentía las piernas. Con el brazo libre pude coger el móvil, lo encendí y vi que estaba casi sin batería, sólo podía hacer una llamada. Con los ojos borrosos intentaba llamar a urgencias; sin fuerzas deposité todas mis esperanzas en aquella única llamada, sabiendo que si pasaba más de media hora no me encontrarían con vida. Con torpeza encontré el número que tenía en la agenda. En ese momento sonó el móvil, era un mensaje Vodafone dándome la bienvenida al servicio y anunciando una nueva promoción con interesantes tarifas. La batería se terminó del todo.

Elena González Rabazo. $2^{\circ}$ Bachillerato. CC.SS. "El móvil”

Me mira con ojos agresivos; creo que le he decepcionado; no recibe lo que quiere de mí. Una terrible idea me ataca constantemente... Cualquier día me abandona sin arrepentirse de haberlo hecho.

Ya viene... me toma con brusquedad y con rabia y después de sujetarme con fuerza y mirarme fijamente me arroja a la cama como una basura. Es definitivo: saldrá a buscar otro mejor que yo...

\section{Raúl Trapero Carrasco. $2^{\circ}$ Bachillerato. CC.SS. "Sin título"}

El sol brillaba en lo alto y calentaba como de costumbre por esos días de junio. Después de intensas horas de búsqueda, el perro de Gustavo, más muerto que vivo por el trato que su amo tuvo con él durante años, pareció excitarse súbitamente y comenzó la carrera entre los pastizales. Yo, con la cara seca y surcada por la huella de mis últimas lágrimas, caminaba con seria dificultad a causa de mi cojera delante de los guardias, que avisaron con una voz de “¡aquí!” al reunirse con el famélico perro. El hedor era insoportable y la sangre aún fresca huía por la garganta de mi hermano. 
La verdad es que aquí encerrado hoy todavía no sé cómo llegó hasta allí mi querido Luis, con lo bien que lo dejé enterrado en el sótano.

\section{Guía-decálogo para escribir un microrrelato en 10 pasos}

A continuación se muestra una guía-decálogo para escribir un microrrelato en 10 pasos, la cual fue diseñada como material para el taller de escritura de los microrrelatos. Este decálogo presenta un cariz eminentemente didáctico. Está adaptado de tres fuentes (Romano, 2008; Rodríguez, 2013; Cumbreño, 2007).

1. Piensa en un hecho o anécdota sobre la que hayas reflexionado. El hecho que elijas debe ser muy breve y gráfico. No debes resumir una historia larga. El interés del microrrelato está en su inmediatez.

2. La experiencia elegida debe contener una tensión entre lo que se cuenta y lo que no se dice. Debe ser aparentemente intrascendente pero profundamente trascendental.

3. Una vez elegida la idea, debes pensar en el punto de vista que vas a emplear para contarla: primera persona, tercera persona, narrador testigo, etc.

4. Piensa en un título sugerente, corto, significativo pero misterioso. Debe revelar algo que falte en la historia, pero sin acabar de completar su significado.

5. El principio es importante para ubicar rápidamente al lector, pero lo más importante es el final, que debe ser sorprendente. Por tanto, piensa antes de nada la primera y la última frase de tu microrrelato. Sobre ellas podrás construir la historia.

6. Cuenta solo lo esencial de la historia. No des explicaciones. Sáltate aquello que no sea imprescindible. Puedes incluso omitir secuencias para que el lector las rellene de sentido. Puedes comenzar in medias res. El lector se ocupará de pensar en qué ha ocurrido antes, y en qué puede pasar después (los finales abiertos son muy recomendables).

7. El poder de este género está en la economía de medios. Reduce los locativos espacio-temporales a lo mínimo indispensable, o suprímelos del todo. El tempo de la acción ha de ser necesariamente breve. No interesa la evolución ni la caracterización; tampoco las descripciones. No utilices más de dos o tres personajes.

8. Acción, acción, acción. Cuenta cosas. El microrrelato es esencialmente narrativo.

9. Tentaciones que deben evitarse, según Cumbreño: "La de no pasar de ocurrencia más o menos ingeniosa; la de quedarse en simple chiste; la de ser solo un cuento corto; la de cometer al mismo tiempo todos los pecados anteriores" $(2007,17)$.

10. Una vez que lo hayas concluido, piensa si puedes suprimir palabras, frases o nexos a fin de que el texto sea más breve. Muchas veces, cuanto más corto, el cuento cuenta más cosas porque es más abierto, más sugerente. 


\section{Conclusiones}

Conviene subrayar, para cerrar el estudio, las claves de la idoneidad del uso del microrrelato en el aula:

1. Se adecúa al currículum y a la metodología (del enfoque comunicativo) de los currículos oficiales de secundaria

2. El género, por su brevedad, constituye un estímulo para incentivar el gusto por la literatura (pequeñas dosis).

3. Con una correcta planificación, la enseñanza-aprendizaje del microrrelato desarrolla todas las destrezas o macrohabilidades lingüísticas.

4. El género se adapta perfectamente al uso de las nuevas tecnologías (twitter, blogs, glogs, concursos en red).

5. Su enseñanza propicia el trabajo individual y en grupo así como la participación activa.

6. El aula puede convertirse en un auténtico "escenario comunicativo".

7. La metodología debe inspirarse en el aprendizaje guiado. Debe comenzarse directamente por los textos; después los alumnos descubren las características del género a través de preguntas guiadas; seguidamente se recomiendan actividades de creación e investigación (orales y escritas) que integren la expresión de los propios gustos personales.

8. A través de un correcto proceso de enseñanza-aprendizaje, la didáctica del microrrelato presenta algunos de los criterios generales de una buena actividad: reto, creatividad, imaginación, carácter lúdico, trabajo en grupo e individual, desarrollo de las cuatro destrezas comunicativas, creación de materiales auténticos, etc.

\section{Bibliografía}

Andrés, Irene (2007): "El microrrelato: caracterización y limitación del género", en Gómez, T. (ed.), Mundos mínimos. El microrrelato en la literatura española contemporánea, Gijón, Llibros del Pexe, 11-40.

Arias, Ángel Manuel; A. M. Calvo y J. L. Hernández (2009): "El microrelato como reclamo. La persuasión retórica de la imagen y la palabra", en Montesa, S. (ed.), Narrativas de la posmodernidad. Del cuento al microrrelato, Málaga, UMA, 529-552.

Ausubel, David Paul; J. D. Novak y H. Hanesian (1983): Psicología educativa, México, Trillas.

Bamidele, Danuta (2010): "Competencia literaria, literatura hipertextual y microrrelatos en el aula de ELE" [en línea], RedELE, 11, 1-162. http://www.educación.gob.es/redele/Bi blioteca2010/DanutaOyewo.html [Consulta: 16 enero 2016]

Brasca, R. (2007): "De la pequeña entrada al ancho del mundo: lineamientos para un taller de microficción", Textos, 46, monografía: "Las minificciones en el aula", 26-38.

Coll, C. (1984): "Estructura grupal, interacción entre alumnos y aprendizaje escolar", Infancia y aprendizaje, 27-28, 119-138.

Cumbreño, José María (2007): "La parte por el todo o cómo sobrevivir con sopas de sobre (Poética)", en Cumbreño, J. M. (ed.), Relatos relámpago, Mérida, ERE, 15-18. 
Fernández-Cuesta, María Gracia (2013): "El microrrelato: origen, características y evolución. Propuesta didáctica en el aula de L2. Aplicaciones prácticas en L1" [en línea], RedEle, 14, 1-121. http://www.mecd.gob.es/redele/Biblioteca-Virtual/2013/memorias -master/Gracias-FernandezC.html [Consulta: 9 mayo 2015]

Fernández, José Luis (2010): "El microrrelato en Hispanoamérica: dos hitos para una historiografía / nuevas prácticas de escritura y de lectura publicado por vez primera", Literatura y Lingüística, 21, 45-54.

García, Gloria (1995): Didáctica de la Literatura para la enseñanza primaria y secundaria, Madrid, Akal.

Gómez, Teresa (ed.). (2007): Mundos mínimos. El microrrelato en la literatura española contemporánea, Gijón, Llibros del Pexe.

González, Henry (2004): "La didáctica del minicuento y su desarrollo en ambientes hipermediales", en Noguerol, F. (ed.), Escritos disconformes. Nuevos modelos de lectura, Salamanca, Universidad de Salamanca, 301-314.

Hernández Mirón, Juan Luis (2010): "Manifestaciones de la estética posmoderna en la aparición y desarrollo del microrrelato" [en línea], Analeta malacitana, 29. http://www.anmal. uma.es/numero29/Microrrelato.htm [Consulta: 2 septiembre 2015]

Juárez, Pablo (1998): "Cómo hacer un taller literario de cuentos en la clase de español como lengua extranjera”, en Moreno, F.; M Gil y K. Alonso (eds.), Actas del VIII Congreso Internacional ASELE. El español como lengua extranjera: del pasado al futuro, Alcalá de Henares, Servicio de Publicaciones de ASELE, 479-486.

Lahoz, Ana (2011): "El microrrelato en aula ELE. Aplicación didáctica" [en línea], MarcoELE, 15, 1-64. http:marcoele.com/descargas/15/Lahoz-microrrelatos.pdf [Consulta: 29 marzo 2015]

Lagmanovich, David (2006): "La extrema brevedad: microrrelatos de una y dos líneas" [en línea], Espéculo. Revista de Estudios Literarios 32. webs.ucm.es/info/especulo/numero32/exbreve.html [Consulta: 28 marzo 2015]

Lagmanovich, David (2007): El microrrelato hispanoamericano, Bogotá, Universidad Pedagógica Nacional.

Lagmanovich, David (2008): "En el territorio de los microtextos", Ínsula, 741, 3-5.

Landero, Luis (2007): “Prólogo", en Cumbreño, J. M. (ed.), Relatos relámpago, Mérida, ERE, 7-11.

Larrea, María Isabel (2004): "Estrategias lectoras en el microcuento", Estudios Filológicos, 39, 179-190.

Latorre Zacarés, Víctor y Mario Máñez Aracil (2004): Microrrelatos. Antología y taller, Valencia, Editilde.

Lorenzin, María Elena (2004): "Fast fiction en la clase de español avanzado: Una experiencia creativa en las antípodas", en Noguerol, F. (ed.), Escritos disconformes. Nuevos modelos de lectura, Salamanca, Ediciones de la Universidad de Salamanca, 317-333.

Martín, Rebeca (2008): "El doble en el microrrelato español del siglo XX”, Ínsula, 741, 9-12. Navascués, Javier de (2004): "Nuevos minicuentos para un nuevo canon: la Antología de la literatura fantástica de Jorge Luis Borges, Adolfo Bioy Casares y Silvina Ocampo", en Noguerol, F. (ed.), Escritos disconformes. Nuevos modelos de lectura, Salamanca, Ediciones de la Universidad de Salamanca, 121-130.

Noguerol, Francisca (ed.) (2004): Escritos disconformes. Nuevos modelos de lectura, Salamanca, Ediciones de la Universidad de Salamanca.

Obligado, Clara (2001): "Prólogo bonsái”, en Obligado, C. (ed.), Por favor, sea breve. Antología de relatos hiperbreves, Madrid, Páginas de Espuma, 9-10. 
Obligado, Clara (2004): "La creación de textos mínimos", en Noguerol, F. (ed.), Escritos disconformes. Nuevos modelos de lectura, Salamanca, Ediciones de la Universidad de Salamanca, 334-344.

Pérez, Ramón (2007): Metapoesía y ficción: Claves de una renovación poética (Generación de los 50-Novísimos), Madrid, Visor.

Ródenas, Domingo (2008): "Contar callando y otras leyes del microrrelato", Ínsula, 741, 6-9.

Rodríguez, María Luisa (2013): "Guía para escribir un microrrelato en español” [en línea]. http://mluisarodriguez.files.wordpress.com/2013/03/guia_para_escribir_un_microrrela to_en_espanol_tour_pdf [Consulta: 16 septiembre 2015]

Romano, Orlando (2008): "Trece consejos para escribir microrrelatos" [en línea]. http:// nalocos.blogspot.com.es/2008/02/trece-consejos-para-escribir.html [Consulta: 13 enero 2016]

Rondón, Amaury (2014): “Juegos didácticos. Una alternativa para el desarrollo de la expresión oral en los niños" [en línea]. http://www.monografias.com/trabajos91/juegos-di dacticos-desarrollo-expresion-oral/juegos-didacticos-desarrollo-expresion-oral2.shtml [Consulta: 4 enero 2016]

Sánchez, Juan y F. Rincón (1984): Propuestas creativas para temas de los Siglos de Oro y $X I X$, Barcelona, PPU.

Santos, Juan Ramón (2007): “Micropoética”, en Cumbreño, J. M. (ed.), Relatos relámpago, Mérida, ERE, 119-120.

Tomassini, Graciela y S. M. Colombo (1999): “La minificción como estrategia pedagógica en los procesos de comprensión y producción textual”, en Zavala, L. (ed.), Lecturas simultáneas. La enseñanza de la lengua y literatura con especial atención al cuento ultracorto, México, UAM, 119-140.

Valls, Fernando (2007): "Para iniciarse en el microrrelato (Algunas sugerencias de lectura)", en Gómez, T. (ed.), Mundos mínimos. El microrrelato en la literatura española contemporánea, Gijón, Llibros del Pexe, 119-132.

Valls, Fernando (2008): “Últimas noticias sobre el microrrelato español”, Ínsula, 741, 2-3. Vigotsky, Lev Semionovich (1985): Pensamiento y lenguaje, Buenos Aires, Pléyade.

Yepes, Enrique (1996). "El microcuento hispanoamericano ante el próximo milenio" [en línea], Revista interamericana de bibliografia, 46, 95-108. http://www.bowdoin.edu/ye pes/profess/microc.htm [Consulta: 16 enero 2016] 